\title{
The Productivity of Strawberry Plants Growing Under Plastic High Tunnels in a Wet Subtropical Environment
}

\author{
Christopher M. Menzel ${ }^{1,3}$, Lindsay A. Smith ${ }^{1}$, \\ and Jenny A. Moisander ${ }^{2}$
}

AdDitionAl INDEX wORDs. breeding lines, climate, cultivars, Fragaria $\times$ ananassa, fruit disease, yield

SUMMARY. The effect of plastic high tunnels on the performance of two strawberry (Fragaria $\times$ ananassa) cultivars (Festival and Rubygem) and two breeding lines was studied in southeastern Queensland, Australia, over 2 years. Production in this area is affected by rain, with direct damage to the fruit and the development of fruit disease before harvest. The main objective of the study was to determine whether plants growing under tunnels had less rain damage, a lower incidence of disease, and higher yields than plants growing outdoors. Plants growing under the tunnels or outdoors had at best only small differences in leaf, crown, root, and flower and immature fruit dry weight. These responses were associated with relatively similar temperatures and relative humidities in the two growing environments. Marketable yields were $38 \%$ higher under the tunnels compared with yields outdoors in year 1 , and $24 \%$ higher in year 2 , mainly due to less rain damage. There were only small differences in the incidences of grey mold (Botrytis cinerea) and small and misshaped fruit in the plants growing under the tunnels and outdoors. There were also only small differences in postharvest quality, total soluble solids, and titratable acidity between the two environments. These results highlight the potential of plastic high tunnels for strawberry plants growing in subtropical areas that receive significant rainfall during the production season.

S trawberry growers in Australia produce $\approx 72,000 \mathrm{t}$ of fruit worth AU\$400 million each year (Menzel and Smith, 2011, 2012a; Menzel and Toldi, 2010). The main production centers are located in Queensland, Victoria, and Western Australia, with production in Queensland worth AU\$180 million. There are smaller industries in New South Wales, South Australia, and Tasmania. Production in southeastern Queensland is severely affected by rain most seasons. The fruit can be damaged directly by rain, with water soaking, surface etching, and cracking (Herrington et al., $2009,2013)$. There can also be an effect on pollination, with distorted berries following short periods of wet weather. Cultivars vary in their sensitivity to direct rain damage; however,

We thank Horticulture Australia Limited (HAL) and the Florida Strawberry Growers' Association for supporting this research.

${ }^{1}$ Department of Agriculture, Fisheries and Forestry, P.O. Box 5083, Sunshine Coast Mail Center, Nambour, Queensland 4560, Australia

${ }^{2}$ Driscoll's Australia, 180 Landershute Road, Palmwoods, Queensland 4555, Australia

${ }^{3}$ Corresponding author. E-mail: chris.menzel@ daff.qld.gov.au. nearly all are affected when the fruit are mature. Herrington et al. (2011) showed that $60 \mathrm{~mm}$ of rain over $3 \mathrm{~d}$ damaged more than $60 \%$ of the crop in 'Rubygem' and 'Festival'.

Strawberry production in southeastern Queensland is also affected by fruit disease, which is promoted by direct rain contact or by high humidity. These diseases are mainly grey mold, powdery mildew (Podosphaera aphanis), stem-end rot (Gnomoniopsis fructicola), and black spot (Colletotrichum acutatum). Powdery mildew and stem-end rot affect both the leaves and the developing fruit. These diseases are mainly controlled by the application of fungicides. However, there are several problems with many of the products used by industry.
Some of these chemicals are ineffective under wet weather, have limits to the number of applications allowed in a season, or may become ineffective in the long term because of the development of resistance in the different fungi (Washington et al., 1999).

Xiao et al. (2001) examined the effect of plastic tunnels on the incidence of fruit disease in strawberry plants in Florida over 2 years. Two cultivars were grown in tunnels or outdoors with different fungicide schedules. The mean incidence of grey mold was $88 \%$ to $94 \%$ lower in the plants growing under tunnels than in the plants growing outdoors. This work indicated that losses because of grey mold can be reduced by the use of tunnels.

Most of the research on plastic tunnels in strawberry has been conducted in Europe, the United States, and Canada (Evenhuis and Wanten, 2006; Neri et al., 2012; Önal, 2000; Rowley et al., 2011; Wallace and Webb, 2013). In these environments, the emphasis of the research has been to develop strategies to extend the production season or protect the crop from extreme weather. There have been some studies in California and Florida that are relevant to production in Queensland (Daugovish and Larson, 2009; Kadir et al., 2006; Larson et al., 2009; Salamé-Donoso et al., 2010; Santos, 2013). It is much drier in California than in Queensland. Rain is also less of an issue in Florida, with more concerns about cold weather.

An analysis of the experiments conducted in California and Florida indicates that tunnels generally increased yields and profitability compared with the performance of plants grown outdoors. Greater production was usually associated with earlier cropping, and protection from frosts and rain. There was generally less grey mold in the fruit grown under plastic.

\begin{tabular}{llll}
\hline $\begin{array}{l}\text { Units } \\
\text { To convert U.S. to SI, } \\
\text { multiply by }\end{array}$ & U.S. unit & SI unit & $\begin{array}{l}\text { To convert SI to U.S., } \\
\text { multiply by }\end{array}$ \\
\hline 0.4047 & acre $(\mathrm{s})$ & $\mathrm{ha}$ & 2.4711 \\
100 & $\mathrm{bar}$ & $\mathrm{kPa}$ & 0.01 \\
0.3048 & $\mathrm{ft}$ & $\mathrm{m}$ & 3.2808 \\
2.54 & inch $(\mathrm{es})$ & $\mathrm{cm}$ & 0.3937 \\
25.4 & inch(es) & $\mathrm{mm}$ & 0.0394 \\
1 & micron $(\mathrm{s})$ & $\mu \mathrm{m}$ & 1 \\
28.3495 & $\mathrm{oz}$ & $\mathrm{g}$ & 0.0353 \\
$\left({ }^{\circ} \mathrm{F}-32\right) \div 1.8$ & ${ }^{\circ} \mathrm{F}$ & ${ }^{\circ} \mathrm{C}$ & $\left({ }^{\circ} \mathrm{C} \times 1.8\right)+32$
\end{tabular}


Differences in fruit quality in the plants grown under tunnels or outdoors in the United States were usually small, with mixed effects on fruit size, fruit appearance, levels of sugars or soluble solids, and taste.

We report on the effect of plastic high tunnels on the performance of two strawberry cultivars and two breeding lines growing in southeastern Queensland, Australia, over 2 years. The plants were grown under tunnels or outdoors. Information was collected on plant growth, yield, and the losses of fruit due to rain, disease, and other defects. Data were also collected on the levels of soluble solids and total acidity in the fruit, and the shelf life of the crop after harvest. We proposed that marketable yield and fruit quality would be better in the plants growing under the tunnels because the plants would be protected from wet weather. Hail and frosts are not major problems for strawberry growers in southeastern Queensland.

\section{Materials and methods}

Bare-rooted transplants of 'Festival', 'Rubygem', and two breeding lines (Breeding Lines 1 and 2) were planted on 21 Mar. 2012 and on 21 Mar. 2013 at Palmwoods in southeastern Queensland, Australia (lat. 26.6 $6^{\circ} \mathrm{S}$, long. $152.9^{\circ} \mathrm{E}$, elevation $29 \mathrm{~m}$ ). The transplants were grown at Stanthorpe in southern Queensland (lat. 28.6 ${ }^{\circ} \mathrm{S}$, long. $152.0^{\circ} \mathrm{E}$, elevation $872 \mathrm{~m}$ ) and were supplied with three to four leaves on each plant (Menzel and Smith, 2012b). 'Festival' and 'Rubygem' account for $\approx 65 \%$ of production in southeastern Queensland. The two breeding lines are currently being evaluated for their performance in this subtropical growing area. They have similar production cycles as the two main cultivars and larger fruit, but are softer, and potentially more susceptible to rain damage and disease.

The plants were grown under plastic high tunnels or in open, outdoor plots as described by Vock (1997). The new plants were planted through plastic, in double row beds $70 \mathrm{~cm}$ wide and $130 \mathrm{~cm}$ apart from the centers. The plants were spaced at $30-\mathrm{cm}$ intervals within the rows, giving a density of 51,000 plants/ha. The plants were irrigated through the use of drip tape placed under the plastic. They were watered when the soil water potential in the root zone decreased below $-10 \mathrm{kPa}$.

The plastic structures used were standard Haygrove tunnels, which are used extensively in the United Kingdom, Australia, and other places (Haygrove, Ledbury, UK). The tunnels were $8 \mathrm{~m}$ wide and $5 \mathrm{~m}$ high. The polythene plastic film was $200 \mu \mathrm{m}$ thick and has a lifespan of 3 to 6 years (THP Luminance; BPI Visqueen Horticultural Products, Stevenston, UK). Each tunnel had four rows of strawberry plants, with the experimental plants planted in the two middle rows. The plots for each treatment were $8 \mathrm{~m}$ long. There were four blocks, with two blocks in each of two tunnels (southern and northern ends), and two blocks on either side of the tunnels for the open plots. In the tunnels, the southern end of each tunnel received no direct sunlight from outside, whereas in the northern end of each tunnel, the plots received some direct sunlight in the morning. There was about $3 \mathrm{~m}$ of row between the southern and northern blocks in the middle of each tunnel. There was a similar gap between the southern and northern blocks in the outdoor plots.

The plastic was placed over the plants growing in the tunnels in midMay 2012 and in mid-Apr. 2013, while the sides of the tunnels were raised during warm weather to moderate temperatures close to the plants. The plants in the two growing environments received similar spray applications for the control of pest and disease (Vock, 1997). The only exception to this pattern was that the plants growing under the tunnels received a few additional sprays to control powdery mildew.

Data were collected on the number of leaves/plant, and plant dry weight (leaves, crowns, roots, flowers, and immature fruit) every 4 weeks from late May to mid-Oct. 2012 (equivalent to late November to midApril in the northern hemisphere), and from late April to mid-Sept. 2013 (equivalent to late October to midMarch). Fruit were harvested every week for an assessment of marketable yield (fresh weight), number of fruit/ plant and average fruit fresh weight from late May to mid-Oct. 2012 or from mid-May to mid-Sept. 2013. Mature fruit were classified as those that were at least three-quartered colored. Average seasonal fruit fresh weight is the long-term average value of fruit fresh weight in a treatment pooled across all harvests (marketable fruit).

A record was kept of the number of fruit that were affected by rain, grey mold, or both, along with those that were small (less than $12 \mathrm{~g}$ fresh weight), misshaped, or both, or that had other defects (mainly other disease, surface bronzing, or bird damage). Fruit that were affected by rain and grey mold were rated as affected by grey mold. Fruit that were small and misshaped were rated as misshaped. The incidence of other fruit disease, including stem-end rot, powdery mildew, and black spot during the study was low. The experiment was laid out in a split-plot design, with growing systems as the main plots and cultivars/breeding lines in the split-plots, with four replications. The main plots were arranged in randomized blocks, and the cultivars/breeding lines randomized in each of the main plots.

Four times over the growing season, eight sound mature fruit were collected from each plot for an assessment of postharvest quality. The fruit from each plot were placed in 250 -g baskets, and stored in the dark at $5{ }^{\circ} \mathrm{C}$ for $5 \mathrm{~d}$. They were then stored at room temperature $\left(15\right.$ to $\left.25^{\circ} \mathrm{C}\right)$ for a further $2 \mathrm{~d}$, and each fruit in the container scored for cracks, watersoaking, discolouration of the skin and disease (mostly grey mold).

Three times over the growing season, six sound mature fruit were collected from each plot for an assessment of total soluble solids content, and titratable acidity as citric acid measured at $20{ }^{\circ} \mathrm{C}$ (Kallio et al., 2000). These authors indicated that total soluble solids content and concentrations of sugars (fructose, glucose, and sucrose) were strongly correlated in strawberry. The sugars accounted for $\approx 90 \%$ of the soluble solids in the fruit. The fruit from each plot were placed in small snap lock resealable bags $(18 \times 17 \mathrm{~cm}$; Glad, Sydney, Australia), and frozen at $-18{ }^{\circ} \mathrm{C}$ until used for chemical analysis. The samples used for the postharvest and fruit chemistry assessments were collected after wet and dry periods. The data on fruit chemistry are presented on a fresh weight basis. 
There were two sections in each block, one for recording plant growth, and an adjacent one for recording yield, defects, and fruit quality. For the growth data, the experiment was laid out in a split-plot design, with the two growing systems as the main plots, the two cultivars and two breeding lines in the subplots, and the different harvests used as additional replication (four blocks $\times$ two plants harvested each time $=$ eight plants per treatment). For the data on marketable yield, average seasonal fruit fresh weight, and fruit defects during the season, the experiment was laid out in a split-plot design, with the two growing systems as the main plots, and the two cultivars and two breeding lines in the split plots (four blocks $\times 30$ plants in each plot $=120$ plants per treatment), and the different harvests used as additional replication. For the data on fruit solids and acidity, and postharvest defects, the experiment was laid out in a split-split-plot design, with the two growing systems as the main plots, the two cultivars and two breeding lines in the split plots, and the different harvests in the split-split plots (four blocks $\times$ six or eight fruit per sample).

Growth data were analyzed by split-plot analysis of variance [ANOVA (two growing systems $\times$ four cultivars/ breeding lines)], pooled over the six harvests each season using GenStat (version 15; VSN International, Hemel Hempstead, UK). Data on marketable yield, average seasonal fruit fresh weight, and mean fruit defects over the season were analyzed by split-plot ANOVA (two growing systems $\times$ four cultivars/breeding lines). Data on postharvest quality and fruit solids and acidity were analyzed by split-split-plot ANOVA (two growing systems $\times$ four cultivars/ breeding lines $x$ three or four harvests). The data on the percentage of fruit with different defects before harvest were transformed to arcsine square root before ANOVA. The data on the number of fruit with defects in storage out of a sample of eight were transformed to $\log _{10}(x+1)$ before ANOVA. Treatment means were back-transformed for presentation. Separate analyses were conducted for each year. Treatment means were separated by calculating least significant difference (LSD) from the ANOVAs.

Information was collected on daily minimum and maximum temperatures and relative humidities at the site over the growing season. There were four Tinytag sensors (Gemini Data Loggers, Chichester, UK) outdoors and four sensors under the tunnels in each of four blocks. The sensors were placed in small weather screens located next to the strawberry plants growing along the rows. The sensors were located about $5 \mathrm{~cm}$ above the level of the ground. Mean values over the growing season were analyzed by one-way ANOVA (two growing systems $\times$ four blocks). Data were also collected on daily rainfall with a rain gauge at the site. No information was collected on light levels under the tunnels or outdoors. Wang et al. (2013) showed that various plastic films used in plastic houses in China transmitted at least $80 \%$ of sunlight (400 to $2300 \mathrm{~nm}$ ).

The gross returns from the different treatments were compared using similar analyses as those used to compare marketable yields. The yields (g/plant) from each treatment for each month from May to October were multiplied by the average price received for strawberry in the Brisbane Markets from 2003 to 2006 to give the gross returns for each treatment. The average price for fruit received in May, June, July, August, September, and October used in this analysis was AU\$3.23, AU\$2.28, AU\$1.82, AU\$1.45, AU\$1.13, and AU\$1.61 per 250-g basket, respectively (M. Herrington, unpublished data). Average prices have been relatively stable over the past decade.

\section{Results and discussion}

In the data analyses to examine the effect of growing system and cultivar/breeding line on the performance of the plants, there were many instances when growing system, cultivar/breeding line, or both had a significant effect on plant growth, yield, returns, and the levels of fruit defects before harvest in both years, with $P<$ 0.05 (Table 1). In these analyses, the interaction between growing system and cultivar/breeding line on the performance of the plants was not significant $(P>0.05)$. The data for each year were analyzed separately.

WeAther. Total rainfall during the harvests from late May to midOct. 2012 (equivalent to late November to mid-April in the northern hemisphere) was $357 \mathrm{~mm}$, while total rainfall from mid-May to mid-Sept. 2013 (equivalent to mid-November to mid-March) was $329 \mathrm{~mm}$. These values were lower than the long-term averages for the respective periods $(519$ and $415 \mathrm{~mm})$. During fruit production, there was more than $10 \mathrm{~mm} /$ week in about half the weeks before each harvest (Fig. 1). There were only small differences in average mean daily temperatures and average mean daily relative humidities between the two growing environments (Table 2). Maximum and minimum temperatures in July and August during the coldest weather were similar in the two environments (data not presented).

Plant growth. In 2012, growing system had no significant $(P>$ 0.05 ) effect on leaf and crown growth, and flower and immature fruit growth (Table 3 ). In contrast, the roots of the plants growing under the tunnels were smaller than the roots of the plants growing outdoors. In 2013 , the plants growing under the tunnels had slightly higher leaf dry weights than the plants growing outdoors, and slightly lower crown and root dry weights. Once again, the two groups of plants had similar levels of flower and immature fruit growth. The lower crown and root growth under the tunnels in 2013 may reflect less light under the plastic (Wang et al., 2013).

The 'Festival' and 'Rubygem' plants generally had more vegetative growth than the other plants (Table $3)$. In 2012, 'Festival', Breeding Line 1 , and 'Rubygem' had higher flower and immature fruit dry weights than Breeding Line 2, whereas in 2013, there were no significant differences. Across all the treatments, the dry weights of leaves, crowns and roots were similar in the two seasons, while the dry weight of the flowers and immature fruit was slightly higher in 2012 than in 2013.

MARKETABLE YIELD, FRUIT FRESH WEIGHT, AND RETURNS. Yields were $38 \%$ higher in the plants growing under the tunnels than in the plants growing outdoors in 2012, and $24 \%$ higher in 2013 (Table 3). There were also differences in the productivity of the two cultivars and two breeding lines. In 2012, yield was lower in Breeding Line 2, intermediate in Breeding Line 1 and 'Rubygem', and higher in 'Festival'. In 2013, yield 
Table 1. Results of the analysis of variance used to analyze the effect of growing system and cultivar/breeding line on the performance of strawberry plants growing at Palmwoods (southeastern Queensland, Australia) in 2012 and 2013. Two cultivars and two breeding lines were grown under plastic high tunnels or outdoors. There was no significant $(P>0.05)$ interaction between growing system and cultivar/breeding line on yield, returns, plant growth, and preharvest defects. The data for each year were analyzed separately.

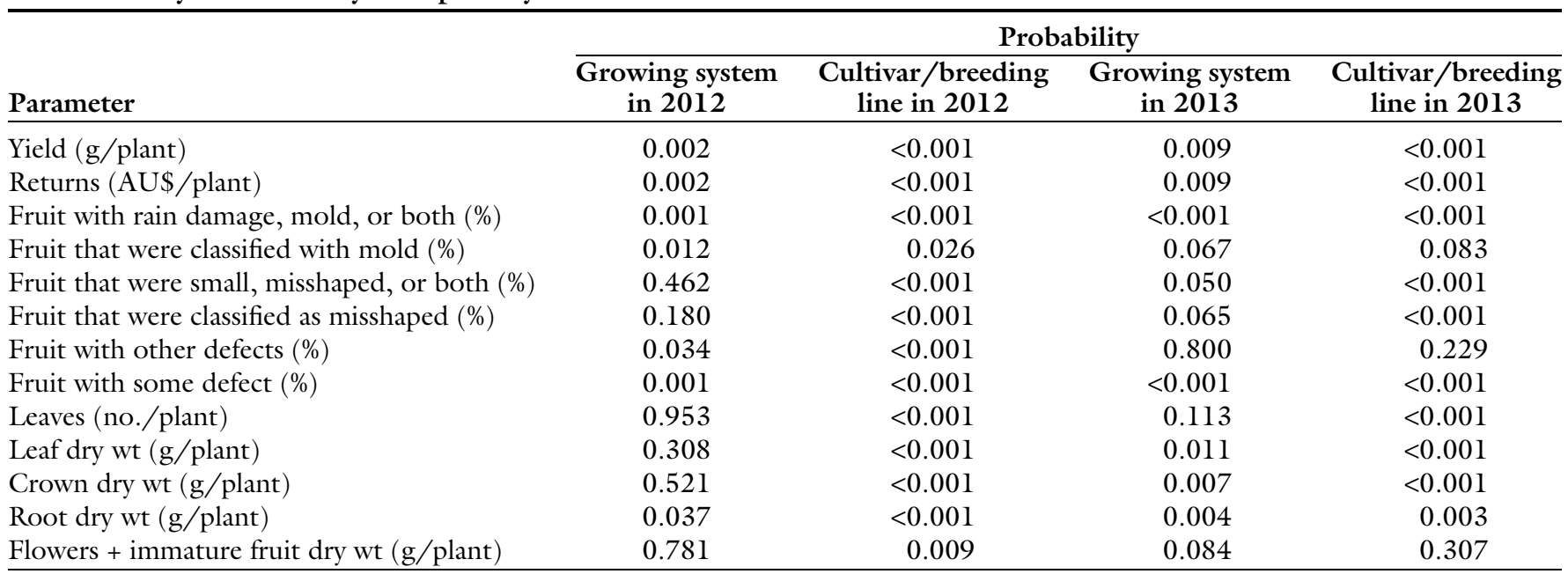

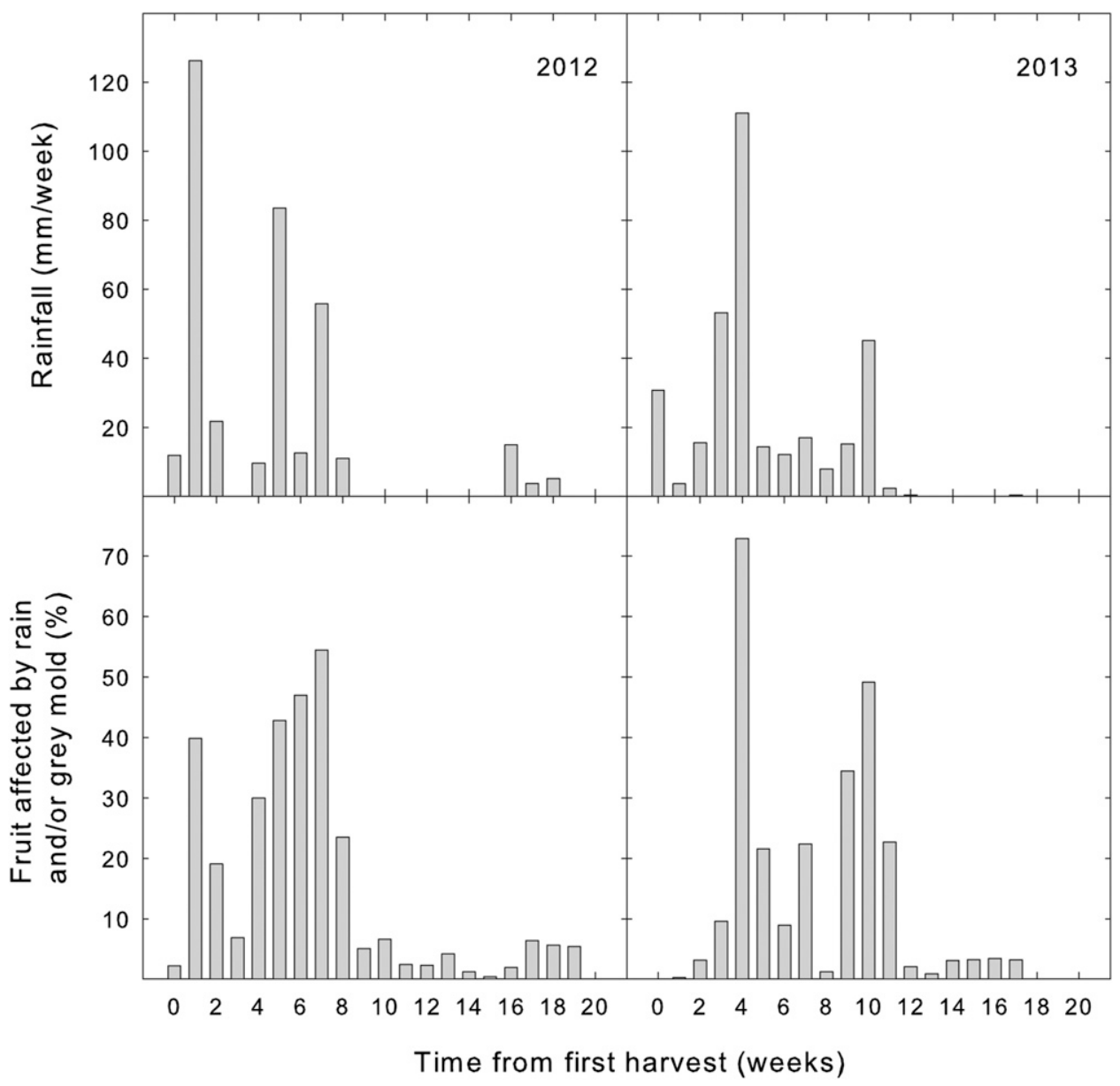

Fig. 1. Pattern of rainfall and the incidence of rain damage, grey mold, or both during the study on four strawberry cultivars / breeding lines that were grown under plastic high tunnels or outdoors at Palmwoods (southeastern Queensland, Australia) in 2012 and 2013. In 2012, the first fruit were harvested on 30 May and the last fruit harvested on 10 Oct. In 2013, the first fruit were harvested on 15 May and the last fruit harvested on 11 Sept. Data show the rainfall in the week before the fruit were harvested (starting from 23 May 2012 or 8 May 2013). Total rainfall over the period was $357 \mathrm{~mm}(14.1$ inch) in 2012 and $329 \mathrm{~mm}$ (13.0 inch) in 2013. Data on the incidence of rain damage, grey mold, or both are the means of 16 replicates pooled across two cultivars and two breeding lines for the plants grown outdoors and have been back-transformed $(\mathrm{N}=18$ or 20 harvests $) ; \mathrm{mm}=0.0394$ inch. 
was lower in 'Rubygem' than in the other plants. There were no significant differences in average seasonal fruit fresh weight across the two growing systems (Table 3 ). In contrast, average seasonal fruit fresh weight was higher in the two breeding lines than in the other plants. Average yield pooled across all of the treatments was higher in 2012 than in 2013, while average seasonal fruit fresh weight was lower. The plants growing under the tunnels and outdoors had similar patterns of fruit production, which generally increased as the season progressed (data not presented).

Returns reflected marketable yields. In 2012, returns were higher in the plants under the tunnels (AU \$6.10/plant) than in the plants outdoors (AU\$4.43/plant) (LSD $P=$ 0.05 and 0.48 , respectively). Returns were slightly lower in 2013 , with the tunnel plants once again more profitable (AU\$4.54/plant) than the outdoor plants (AU $\$ 3.57 /$ plant) (LSD $P=0.05$ and 0.51 , respectively). Relative returns across the different cultivars and breeding lines reflected their productivity (data not presented).

Salamé-Donoso et al. (2010) indicated that marketable yields were increased by $50 \%$ and $63 \%$ in plants grown under tunnels compared with the yields of plants grown outdoors over two seasons in Florida. The higher yields under the tunnels were mainly due to less frost damage. Later work by Santos (2013) showed a strong correlation $(r=0.81)$ between the increase in yield over the season under tunnels compared with the yields outdoors, and the number of nights below $2{ }^{\circ} \mathrm{C}$ in the outside environment requiring freeze protection using supplementary sprinkler irrigation. Marketable yields were increased by an average of $51 \%$ across 15 plantings when the plants were grown under tunnels compared with the yields of the plants grown outdoors. In similar work conducted in California, early yields under tunnels were higher than those outdoors, reflecting fewer rain-damaged, moldy, and misshaped fruit (Daugovish and Larson, 2009). Yields under the tunnels were reduced at other times because of high temperatures. The main benefit of the tunnels in our study was to protect the fruit from rain. Total rainfall was slightly higher in $2012(357 \mathrm{~mm})$ than in 2013
(329 $\mathrm{mm})$, and it was slightly wetter toward the end of the first experiment. There were no frosts or hail during our study.

Average returns were about AU $\$ 1.50 /$ plant more for the plants growing under the tunnels than for the plants growing outdoors. This was equivalent to an increase of $38 \%$ for the plants growing under the tunnels. The average difference in marketable yields between the two groups of plants was $31 \%$. The plants under the tunnels benefited by having more marketable fruit in May and June when the crop is more valuable.

The cost of high tunnels is about AU $\$ 100,000$ per hectare, including steel, fittings, and the plastic (D. Phillips and A. Reed, unpublished data). Constructions costs add another AU\$15,000/ha. The increase in profit for the plants growing under the tunnels compared with the plants growing outdoors is $\approx \mathrm{AU} \$ 38,250$, after taking into account the extra costs associated with picking, packing, and marketing the larger crop of $\approx$ AU $\$ 0.75 /$ plant (Queensland Strawberry Growers' Association, 2014). This analysis indicates that it would take about 3 years to cover the initial costs of the tunnels.

Fruit DEFECTs. Average losses of production due to fruit defects were $\approx 50 \%$ greater in the plants growing outdoors than in the plants growing under the tunnels (Table 4). About a quarter of the losses outdoors were due to rain damage, grey mold, or both. Within this classification, most of the fruit were damaged by rain. The rest of the fruit were mainly culled because they were small, misshaped, or both. Within this classification, most of the fruit were small. Differences in the incidence of mold between the two growing zones were small (2012) or not significant (2013). In 2012, the plants growing in the different environments had similar numbers of small and misshaped fruit, whereas in 2013 , losses due to these defects were slightly higher in the plants under the tunnels. Average losses due to all defects across the two growing systems were higher in 'Rubygem' than in the other cultivar and the breeding lines (Table $4)$. Most of the fruit were culled in this cultivar because they were small, misshaped, or both. 
Table 3. Effect of growing system and cultivar/breeding line on average seasonal leaf growth and dry matter production, total marketable yield and average seasonal fruit fresh weight in strawberry plants growing at Palmwoods (southeastern Queensland, Australia) in 2012 and 2013. The plants were grown under plastic high tunnels or outdoors.

\begin{tabular}{|c|c|c|c|c|c|c|c|}
\hline \multirow{2}{*}{$\begin{array}{l}\text { Growing system or } \\
\text { cultivar/breeding line }\end{array}$} & \multirow{2}{*}{$\begin{array}{c}\text { Leaves } \\
(\text { no. } / \text { plant })^{\mathrm{z}}\end{array}$} & \multicolumn{4}{|c|}{ Dry wt $(g / \text { plant })^{z}$} & \multirow{2}{*}{$\begin{array}{c}\text { Yield } \\
(\mathrm{g} / \text { plant })^{\mathrm{z}}\end{array}$} & \multirow{2}{*}{$\begin{array}{c}\text { Avg fruit } \\
\text { fresh wt }(g)^{\mathrm{z}}\end{array}$} \\
\hline & & Leaves & Crowns & Roots & Flowers + immature fruit & & \\
\hline \multicolumn{8}{|c|}{2012} \\
\hline Tunnel & $27.6 \mathrm{a}$ & $19.2 \mathrm{a}$ & $5.6 \mathrm{a}$ & $2.1 \mathrm{a}$ & $10.7 \mathrm{a}$ & $991 \mathrm{~b}$ & $23.5 \mathrm{a}$ \\
\hline Festival & $39.0 \mathrm{~d}$ & $25.0 \mathrm{c}$ & $7.7 \mathrm{c}$ & $3.0 \mathrm{c}$ & $11.0 \mathrm{~b}$ & $1064 \mathrm{c}$ & $19.8 \mathrm{a}$ \\
\hline Breeding Line 1 & $23.2 \mathrm{~b}$ & $13.7 \mathrm{a}$ & $4.3 \mathrm{a}$ & $2.1 \mathrm{ab}$ & $11.7 \mathrm{~b}$ & $868 \mathrm{~b}$ & $28.1 \mathrm{~d}$ \\
\hline \multicolumn{8}{|c|}{2013} \\
\hline Outdoor & $20.3 \mathrm{a}$ & $16.3 \mathrm{a}$ & $4.6 \mathrm{~b}$ & $2.7 \mathrm{~b}$ & $9.0 \mathrm{a}$ & $479 \mathrm{a}$ & $28.7 \mathrm{a}$ \\
\hline Tunnel & $21.3 \mathrm{a}$ & $17.3 \mathrm{~b}$ & $4.3 \mathrm{a}$ & $2.2 \mathrm{a}$ & $8.3 \mathrm{a}$ & $594 \mathrm{~b}$ & $28.2 \mathrm{a}$ \\
\hline Festival & $25.5 \mathrm{~d}$ & $18.9 \mathrm{c}$ & $5.0 \mathrm{~b}$ & $2.6 \mathrm{~b}$ & $9.2 \mathrm{a}$ & $582 \mathrm{~b}$ & $23.9 \mathrm{a}$ \\
\hline
\end{tabular}

${ }^{z}$ Data for growth are the means of 48 or 96 replicates per treatment, pooled across the two growing systems or the two cultivars and two breeding lines (six harvests). Data for yield and fruit weight are the means of 8 or 16 replicates per treatment, pooled across the two growing systems or the two cultivars and two breeding lines; $1 \mathrm{~g}=0.0353$ oz. y Means in a column for the two main effects followed by different letters are significantly different at $P=0.05$. Data for each year were analyzed separately.

Table 4. Effect of growing system and cultivar/breeding line on the percentage of fruit with various defects in strawberry plants growing at Palmwoods (southeastern Queensland, Australia) in 2012 and 2013. The plants were grown under plastic high tunnels or outdoors.

\begin{tabular}{|c|c|c|c|c|c|c|}
\hline $\begin{array}{l}\text { Growing system } \\
\text { or cultivar/ } \\
\text { breeding line }\end{array}$ & $\begin{array}{l}\text { Fruit with rain } \\
\text { damage and/or } \\
\text { mold }(\%)^{\mathrm{z}}\end{array}$ & $\begin{array}{l}\text { Fruit classified } \\
\text { as affected by } \\
\text { mold }(\%)^{z}\end{array}$ & $\begin{array}{l}\text { Fruit that were } \\
\text { small and/or } \\
\text { misshaped }(\%)^{\mathrm{z}}\end{array}$ & $\begin{array}{l}\text { Fruit that } \\
\text { were classified as } \\
\text { misshaped }(\%)^{\mathrm{z}}\end{array}$ & $\begin{array}{l}\text { Fruit with other } \\
\text { defects }(\%)^{\mathrm{z}}\end{array}$ & $\begin{array}{c}\text { Fruit with some } \\
\text { defect }(\%)^{z}\end{array}$ \\
\hline \multicolumn{7}{|c|}{2012} \\
\hline Outdoor & $11.8 b^{y}$ & $1.3 \mathrm{a}$ & $16.4 \mathrm{a}$ & $3.2 \mathrm{a}$ & $1.4 \mathrm{~b}$ & $39.6 \mathrm{~b}$ \\
\hline Tunnel & $3.7 \mathrm{a}$ & $0.4 \mathrm{~b}$ & $16.2 \mathrm{a}$ & $2.5 \mathrm{a}$ & $0.3 \mathrm{a}$ & $24.7 \mathrm{a}$ \\
\hline Festival & $5.0 \mathrm{a}$ & $0.7 \mathrm{ab}$ & $17.7 \mathrm{c}$ & $2.7 \mathrm{~b}$ & $0.3 \mathrm{a}$ & $29.2 \mathrm{a}$ \\
\hline Rubygem & $8.8 \mathrm{c}$ & $1.1 \mathrm{~b}$ & $25.0 \mathrm{~d}$ & $3.9 \mathrm{c}$ & $0.3 \mathrm{a}$ & $42.2 \mathrm{~b}$ \\
\hline \multicolumn{7}{|c|}{2013} \\
\hline Outdoor & $10.4 \mathrm{~b}$ & $0.6 \mathrm{a}$ & $26.8 \mathrm{a}$ & $3.5 \mathrm{a}$ & $0.1 \mathrm{a}$ & $46.1 \mathrm{~b}$ \\
\hline Tunnel & $1.0 \mathrm{a}$ & $0.2 \mathrm{a}$ & $29.6 \mathrm{~b}$ & $1.6 \mathrm{a}$ & $0.1 \mathrm{a}$ & $33.4 \mathrm{a}$ \\
\hline Festival & $2.8 \mathrm{a}$ & $0.4 \mathrm{a}$ & $34.5 \mathrm{c}$ & $1.3 \mathrm{a}$ & $0.1 \mathrm{a}$ & $42.4 \mathrm{c}$ \\
\hline
\end{tabular}

${ }^{\mathrm{z}}$ Data are the means of 8 or 16 replicates per treatment, pooled across the two growing systems or the two cultivars and two breeding lines. Other defects include mainly other disease, surface bronzing or bird damage. Data are presented as back-transformed means.

${ }^{y}$ Means in a column for the two main effects followed by different letters are significantly different at $P=0.05$. Data for each year were analyzed separately.

Averages total losses were lower in 2012 than in $2013(31.8 \%$ vs. $39.6 \%$, back-transformed means). Losses due to rain damage, grey mold, or both were higher in the first year $(7.2 \%$ vs. $4.6 \%$, back-transformed means), while losses due to small, misshaped fruit, or both were lower in the first year (16.3\% vs. $28.2 \%$, back-transformed means).

Across the four cultivars/breeding lines, more than half the fruit from the plants growing outdoors were affected by rain, grey mold, or both after individual periods of wet weather (Fig. 1). However, the relationship between the percentage of fruit affected and weekly rainfall in the outdoor plots was weak $\left(R^{2}=0.37\right)$. This was possibly because rain in 1 week affected fruit production over several weeks.

The plants growing under the tunnels had higher marketable yields because the fruit were protected from rain. About $2 \%$ of the fruit under the tunnels were affected by rain compared with $\approx 10 \%$ of the fruit growing outdoors. The average incidence of grey mold over the season was less than $1.5 \%$, with only small difference between the plants growing in the two environments. Earlier experiments showed that plants growing in this area were affected by rain most seasons (Herrington et al., 2009, 
$2011,2013)$. More than $80 \%$ of fruit could be damaged, with 'Rubygem' more susceptible than 'Festival', and there was no clear relationship between the incidence of damage and the amount of rain. In our experiment, 'Rubygem' was more susceptible than 'Festival', with the two breeding lines intermediate. Our results suggest a carry-over of damage after rain, and no clear threshold for damage.

As indicated above, the incidence of grey mold was very low in our study, with only small differences in the average rates of infection in the two environments. The maximum rate of infection outdoors during the season was $8 \%$ in 2012 and $5 \%$ in 2013. The low average incidence of infection was probably due to the weather being relatively dry. Xiao et al. (2001) showed that fruit growing under tunnels in Florida had less mold than fruit growing outdoors. In the second year of their study, the incidence of mold was $\approx 1 \%$ under the tunnels (sprayed and control plots) compared with $\approx 11 \%$ outdoors (sprayed and control plots). The incidence of the disease appears to be higher than that found in our study. Burlakoti et al. (2013) indicated a lower incidence of mold under tunnels in Canada, although less than 2\% of the fruit were lost outdoors. In the study conducted in California by Daugovish and Larson (2009), there were only small differences in the incidence of mold between plants under the tunnels or outdoors for 'Camarosa' $(0.3 \%$ vs. $1.2 \%)$, but larger differences for 'Ventana' ( $2.1 \%$ vs. $8.0 \%)$.

The majority of fruit were rejected because they were small, misshaped, or both, with small fruit more common. Overall, there were only minor differences in the levels of these defects across the two growing systems. In California, there was no consistent effect of growing environment on average fruit size across four experiments, although the fruit under the tunnels were rated as more attractive than the fruit growing outdoors (Larson et al., 2009). In our study, average fruit weight was similar in the two growing systems.

The incidence of small fruit was higher during warmer weather at the end of the season. Le Mière et al. (1998) showed that there was a strong relationship between fruit size and temperature in glasshouse experiments in the United Kingdom. Average fruit fresh weight in waitingbed plants decreased from $\approx 14 \mathrm{~g}$ at $12{ }^{\circ} \mathrm{C}$ to $\approx 5 \mathrm{~g}$ at $28{ }^{\circ} \mathrm{C}$. In our experiments, there was also a variation in the incidence of misshaped fruit, with more defects after periods of cool weather. Ariza et al. (2012) showed that the incidence of misshaped fruit in Spain decreased as the average minimum temperature in the 7 weeks before harvest increased from $\approx 0$ to $14{ }^{\circ} \mathrm{C}$. The incidences of small and misshaped fruit were similar in the plants growing under the tunnels and outdoors. This probably reflects the similar temperatures in the two growing systems, with the sides of the tunnels raised to reduce temperatures during warm weather.

In the research conducted in California, Daugovish and Larson (2009) noted that in the first season, temperatures in the tunnels were 1 to $3{ }^{\circ} \mathrm{C}$ higher than outdoors. In the second season, the days were 2 to $4{ }^{\circ} \mathrm{C}$ cooler in the tunnels, while the nights were 2 to $3{ }^{\circ} \mathrm{C}$ warmer. High temperatures in April (northern hemisphere, equivalent to October in the southern hemisphere) reduced subsequent production under the tunnels compared with production outdoors. There was no evidence that high temperatures under the tunnels in the study in Queensland reduced yield or fruit quality compared with the performance of the plants growing under ambient conditions.

Powdery mildew was rare in our experiments, with no differences between the plants growing in the two environments. This is possibly because relative humidity under the tunnels was similar to ambient conditions, and chemical control of the disease was effective. Moderate temperatures and high humidity typically favor the growth of the powdery mildew fungus, with the conidia germinating at temperatures between 15 and $25^{\circ} \mathrm{C}$ when the relative humidity is above $75 \%$ (Kennedy et al., 2013). Studies have shown that the incidence of the disease is higher in plants growing under tunnels than in plants growing outdoors (Burlakoti et al., 2013; Xiao et al., 2001).

Postharvest Quality, TOTAL SOLUBLE SOLIDS, AND TOTAL TITRATABLE ACIDITY. Growing system had no significant $(P>0.05)$ effect on the postharvest quality of the fruit or on fruit soluble solids (Table 5).

Table 5. Effect of growing system and cultivar/breeding line on postharvest quality, and the concentration of fruit soluble solids and total titratable acidity in strawberry plants growing at Palmwoods (southeastern Queensland, Australia) in 2012 and 2013. The plants were grown under plastic high tunnels or outdoors.

\begin{tabular}{lccc}
\hline $\begin{array}{l}\text { Growing system } \\
\text { or cultivar/ } \\
\text { breeding line }\end{array}$ & $\begin{array}{l}\text { Fruit with defects } \\
\text { (no./eight fruit) }\end{array}$ & $\begin{array}{c}\text { Total soluble } \\
\text { solids (\%) }\end{array}$ & $\begin{array}{c}\text { Total titratable } \\
\text { acidity (\%) }\end{array}$ \\
\hline & $1.7 \mathrm{a}^{\mathrm{z}}$ & 2012 & \\
Outdoor & $1.9 \mathrm{a}$ & $7.7 \mathrm{a}$ & $0.63 \mathrm{a}$ \\
Tunnel & $0.9 \mathrm{a}$ & $7.3 \mathrm{a}$ & $0.62 \mathrm{a}$ \\
Festival & $2.2 \mathrm{~b}$ & $8.1 \mathrm{c}$ & $0.62 \mathrm{a}$ \\
Breeding Line 1 & $2.2 \mathrm{~b}$ & $6.8 \mathrm{a}$ & $0.65 \mathrm{a}$ \\
Breeding Line 2 & $2.3 \mathrm{~b}$ & $7.5 \mathrm{~b}$ & $0.62 \mathrm{a}$ \\
Rubygem & $7.6 \mathrm{~b}$ & $0.61 \mathrm{a}$
\end{tabular}

$\begin{array}{llll}\text { Outdoor } & 1.0 \mathrm{a} & 7.6 \mathrm{a} & 0.62 \mathrm{a} \\ \text { Tunnel } & 1.2 \mathrm{a} & 7.6 \mathrm{a} & 0.69 \mathrm{~b} \\ \text { Festival } & 0.9 \mathrm{a} & 7.0 \mathrm{a} & 0.63 \mathrm{a} \\ \text { Breeding Line 1 } & 1.0 \mathrm{a} & 7.4 \mathrm{a} & 0.71 \mathrm{~b} \\ \text { Breeding Line 2 } & 1.1 \mathrm{a} & 8.8 \mathrm{~b} & 0.69 \mathrm{~b} \\ \text { Rubygem } & 1.7 \mathrm{~b} & 7.1 \mathrm{a} & 0.61 \mathrm{a}\end{array}$

${ }^{\mathrm{z}}$ Data are the means of 32 to 64 replicates per treatment, pooled across the two growing systems or the two cultivars and two breeding lines, and over three (soluble solids and acidity) or four sampling periods (postharvest quality). Data on the number of fruit out of eight with defects after harvest are presented as back-transformed means. Fruit were assessed for defects after being stored in the dark at $5^{\circ} \mathrm{C}\left(41.0^{\circ} \mathrm{F}\right)$ for $5 \mathrm{~d}$ and then at room temperature for $2 \mathrm{~d}$. Soluble solids and acidity were measured on freshly harvested fruit.

${ }^{y}$ Means in a column for the two main effects followed by different letters are significantly different at $P=0.05$. Data for each year were analyzed separately. 
There was a mixed effect of growing system on fruit acidity, with no significant $(P>0.05)$ effect in the first year, and higher acidity in the tunnel plants in the second year. In 2012, 'Festival' had fewer defects after being stored than the other cultivar and the breeding lines. In 2013, there was a slightly different pattern, with 'Festival' and the breeding lines better than 'Rubygem'. In 2012, soluble solids were lower in Breeding Line 1, intermediate in Breeding Line 2 and 'Rubygem', and higher in 'Festival', whereas acidity was similar across the cultivars and the breeding lines (Table 5). In 2013, Breeding Line 2 had higher soluble solids than the other plants, while the breeding lines had a higher acidity than 'Festival' and 'Rubygem'.

Average postharvest losses pooled across the two growing systems and the two cultivars and two breeding lines were slightly higher in 2012 than in 2013 (1.8 vs. 1.1 fruit with defects out of eight fruit, back-transformed means). Total soluble solids was similar in the two years $(7.5 \%$ and $7.6 \%)$, while total acidity was lower in 2012 than in $2013(0.63 \%$ and $0.66 \%)$. The values of solids and acidity are similar to those reported for a range of cultivars and selections growing in Florida (Whitaker et al., 2011). The effect of tunnels on soluble solids was generally small in the research initiated in Florida (Salamé-Donoso et al., 2010). In contrast, in another study conducted in Finland, fruit growing under tunnels had lower soluble solids than fruit growing outdoors due to higher temperatures and shading under the structures (Hoppula and Karhu, 2006).

\section{Conclusions}

Strawberry plants growing under high plastic tunnels had higher yields and returns than plants growing outdoors in southeastern Queensland, Australia. This was mainly because the plants growing under the tunnels had fewer fruit damaged by rain. There were only small differences in the relative number of fruit that were affected by grey mold or that were small or misshaped in the two growing environments. Fruit quality after harvest was also similar under the tunnels and outdoors. More than half of the fruit growing outdoors were rejected during short periods of wet weather. High plastic tunnels have the potential to increase the productivity of strawberry fields in subtropical areas that receive significant rain during the growing season. Our results differed from research conducted in other areas where tunnels have been used to protect the crops from frost or hail or to extend the production season.

\section{Literature cited}

Ariza, M.T., C. Soria, J.J. Medina-Mínguez, and E. Martínez-Ferri. 2012. Incidence of misshapen fruits in strawberry plants grown under tunnels is affected by cultivar, planting date, pollination, and low temperatures. HortScience 47:1569-1573.

Burlakoti, R.R., J. Zandstra, and K. Jackson. 2013. Comparison of epidemiology of gray mold, anthracnose fruit rot, and powdery mildew in day-neutral strawberries in field and high-tunnel conditions in Ontario. Intl. J. Fruit Sci. 13:19-27.

Daugovish, O. and K.D. Larson. 2009. Strawberry production with protected culture in southern California. Acta Hort. 842:163-166.

Evenhuis, A. and P.J. Wanten. 2006. Effect of polythene tunnels and cultivars on grey mould caused by Botrytis cinerea in organically grown strawberries. Agr. Conspectus Scientificus 71:111-114.

Herrington, M.E., C. Hardner, M. Wegener, and L.L. Woolcock. 2013. Rain damage on three strawberry cultivars grown in subtropical Queensland. Intl. J. Fruit Sci. 13:52-59.

Herrington, M.E., C. Hardner, M. Wegener, L.L. Woolcock, and M.J. Dieters. 2011. Rain damage to strawberries grown in southeast Queensland: Evaluation and genetic control. HortScience 46:832-837.

Herrington, M.E., L. Woolcock, M. Wegener, M. Dieters, and J. Moisander. 2009. Cultivar differences in tolerance to damage by rainfall. Acta Hort. 842:483486.

Hoppula, K.B. and S.T. Karhu. 2006. Strawberry fruit quality responses to the production environment. J. Food Agr. Environ. 4:166-170.

Kadir, S., E. Carey, and S. Ennahli. 2006. Influence of high tunnel and field conditions on strawberry growth and development. HortScience 41:329-335.

Kallio, H., M. Hakala, A. Pelkkikangas, and A. Lapveteläinen. 2000. Sugars and acids of strawberry varieties. Eur. Food Res. Technol. 212:81-85.
Kennedy, C., T.N. Hasing, N.A. Peres, and V.M. Whitaker. 2013. Evaluation of strawberry species and cultivars for powdery mildew resistance in open-field and high tunnel production systems. HortScience 48:1125-1129.

Larson, K.D., O. Daugovish, and D.V. Shaw. 2009. Optimizing strawberry production and fruit quality with use of protected culture in southern California. Acta Hort. 842:171-176.

Le Mière, P., P. Hadley, J. Darby, and N.H. Battey. 1998. The effect of thermal environment, planting date and crown size on growth, development and yield of Fragaria $\times$ ananassa Duch. J. Hort. Sci. Biotechnol. 73:786-795.

Menzel, C.M. and L. Smith. 2011. Effect of time of planting, plant size, and nurserygrowing environment on the performance of 'Festival' strawberry in a subtropical environment. HortTechnology 21:5666.

Menzel, C.M. and L. Smith. 2012a. Effect of time of planting and plant size on the productivity of 'Festival' and 'Florida Fortuna' strawberry plants in a subtropical environment. HortTechnology 22:330337.

Menzel, C.M. and L. Smith. 2012b. Relationship between the levels of nonstructural carbohydrates, digging date, nursery-growing environment, and chilling in strawberry transplants in a subtropical environment. HortScience 47:459-464.

Menzel, C.M. and A. Toldi. 2010. An evaluation of containerized plants for strawberries growing in a subtropical environment. HortTechnology 20:786-793.

Neri, D., G. Baruzzi, F. Massetani, and W. Faedi. 2012. Strawberry production in forced and protected culture in Europe as a response to climate change. Can. J. Plant Sci. 92:1021-1036.

Önal, K. 2000. Investigations on the performance of some strawberry cultivars (Fragaria $\times$ ananassa Duch.) growing in open fields and under high tunnel conditions. Turk. J. Agr. For. 24:31-36.

Queensland Strawberry Growers' Association. 2014. Queensland strawberry industry average gross returns. 25 Mar. 2014. <http://www.qldstrawberries. com.au/data/gross_margin_2006.htm>.

Rowley, D., B.L. Black, D. Drost, and D. Feuz. 2011. Late-season strawberry production using day-neutral cultivars in high-elevation high tunnels. HortScience 46:1480-1485.

Salamé-Donoso, T.P., B.M. Santos, C.K. Chandler, and S.A. Sargent. 2010. Effect of high tunnels on the growth, yields, and 


\section{Research Reports}

soluble solids of strawberry cultivars in Florida. Intl. J. Fruit Sci. 10:249-263.

Santos, B.M. 2013. Advances on protected culture of berry crops in Florida. J. Amer. Pomol. Soc. 67:11-17.

Vock, N. 1997. Strawberry information kit. Dept. Primary Industries, Nambour, Queensland, Australia.

Wallace, R.W. and C.J. Webb. 2013. Strawberries grown under protected cropping on the Texas high plains. J. Amer. Pomol. Soc. 67:7-10.
Wang, N., C.W. Ma, S.M. Zhao, Y.C. Jiang, and J.X. Song. 2013. Measurement of transmissivity of solar greenhouse covering materials. J. Shenyang Agr. Univ. 44:531-535.

Washington, W.S., S. Engleitner, G. Boontjes, and N. Shanmuganathan. 1999. Effect of fungicides, seaweed extracts, tea tree oil, and fungal agents on fruit rot and yield in strawberry. Austral. J. Exp. Agr. 39:487-494.
Whitaker, V.M., T. Hasing, C.K. Chandler, A. Plotto, and E. Baldwin. 2011. Historical trends in strawberry fruit quality revealed by a trial of University of Florida cultivars and advanced selections. HortScience 46:553-557.

Xiao, C.L., C.K. Chandler, J.F. Price, J.R. Duval, J.C. Mertely, and D.E. Legard. 2001. Comparison of epidemics of botrytis fruit rot and powdery mildew of strawberry in large plastic tunnel and field production systems. Plant Dis. 85:901909. 